\section{"Fiction-in-science" futures}

The groups' work led to four speculative, "fiction-in-science" scenarios: (i) the "Quantified Non-Self" (an extension of the idea of the quantified self) envisions comprehensive monitoring of individuals' microbiomes and their editing to prevent disease conditions as well as to fight the global antibiotic crisis. The scenario proposes startling changes in the perception of our microbial environment and hygiene habits, and imagines changes of cultural practices. (ii) "Life Log: Gene Drive Defense" puts forward different monitor and control mechanisms to reduce potential risks and consequences of gene drives (genetic elements for the rapid, effective spreading of genetic changes in wild populations). (iii) "CRISPiRATES Nation" imagines a state in international waters in which all genome editing (including human germline engineering) is entirely legal and addresses associated ethical, social and political issues. (iv) "Conscious Aesthetics" presents as its theme a startup business selling wearable devices that induce packaged and pre-programmed feelings and sensations through CRISPR-mediated epigenetic changes, and brings up associated questions such as on addiction or the loss of control over oneself.

The scenarios as well as some kitchen-made laboratory devices (produced during the week) were presented in a public session on the afternoon of the last day. The audience included about 30 people mainly from the TU Munich campus, but also representatives of companies and Bavarian authorities in charge with GMO regulation, and journalists. The playful and imaginative, multimedia presentations of the scenarios, which also involved the audience with brief role plays in the case of the "CRISPiRATES Nation", were able to spark various questions from and discussion with the audience, especially on ethical and social aspects related to possible genome editing applications.

\section{Conclusion}

The event with its open exchange and collaboration between experts from within and outside academia led to the joint development of "fiction-in-science" type scenarios on genome editing futures. Even though, or maybe because, these scenarios were not primarily striving to be bound to truly realistic ideas (or what may appear as such), they were able to bring up some less obvious social, ethical and political issues - in addition to more classical ones linked to potential hazards from the environmental release of GMOs and their control/regulation. Among these less obvious points are ethical dilemmas (e.g., linked to enhanced individual competitiveness at the cost of losing self-control) and effects from possible changes in cultural practices and morals, arising from editing genomes and epigenomes in our environment and ourselves.

\section{Disclosure statement}

The author declares that he was a co-applicant for the project grant "GenomHacking: Klausurwoche zu ethischen, rechtlichen und sozialen Aspekten moderner Verfahren der Genom-Editierung und deren möglicher Anwendung", funded by the German Federal Ministry of Education and Research, BMBF (grant number 01GP1684), and that he serves as the project leader.

\section{REPORT \\ RRI in Germany: Reflections on the State of the Art} Report on the workshop "Responsible Research and Innovation in Practice" Karlsruhe, 17 February 2017

\author{
Miltos Ladikas, Institute for Technology Assessment \\ and Systems Analysis (ITAS), Karlsruhe Institute of Technology, \\ Karlstr.11, 76133 Karlsruhe (miltos.ladikas@kit.edu) \\ Julia Hahn, Leonhard Hennen, Pavel Kulakov, Constanze Scherz, \\ Institute for Technology Assessment and Systems Analysis (ITAS), \\ Karlsruhe Institute of Technology (KIT)
}

How do policy ideas from the European context influence national discourses? What questions arise for the stakeholders involved in each country? How are processes and practices adapted? In order to investigate this, a workshop on the state of the art of Responsible Research and Innovation (RRI) was held in Karlsruhe, as part of the EU-funded project "RRI-Practice". The aim was to gather representatives from various organisations and areas in order to gain insights into the diverse discussions and developments regarding responsibility in the context of science and innovation.

Responsible Research and Innovation (RRI) is a concept promoted by the European Commission as a science policy framework that seeks to align technological innovation with broader social values and support institutional decisions concerning the goals and trajectories of research and innovation under conditions of uncertainty, ambiguity and ignorance (Stilgoe et al. 2013). RRI is certainly based on Technology Assessment (TA) processes and methodologies, while attempting to be more inclusive in $\mathrm{S} \& \mathrm{~T}$ issues under discussion (Hahn and Ladikas 2014). It is still under discussion whether RRI fits the various national S \& T structures and, if yes, how. In order to discuss these questions from different points of view, participants came from various organisations representing the research landscape in Germany, including largescale research funding and conducting organisations (Helmholtz

This is an article distributed under the terms of the Creative Commons Attribution License CCBY 4.0 (https://creativecommons.org/licenses/by/4.0/) https://doi.org/10.14512/tatup.26.1-2.85 
Association, Fraunhofer Society, Karlsruhe Institute of Technology) as well as representatives from policy advice (Parliamentary Office of Technology Assessment, Council of Science and Humanities) and civil society (Forschungswende).

There was consensus that researchers and research organisations have certain responsibilities towards society. Mainly this revolved around the need of research and science to communicate and interact with society, with the goal of bringing the aims of science and those of society closer together. This was discussed in the context of the organisations' mission statements that reflect the importance of mutual feedback with society and contextualise their research as something that reflects societal needs. Current research practice was nevertheless criticised as it frames the discussions mainly around problems and focuses on negative challenges instead of on a positive concept of responsibility.

\section{RRI does not provide more value for responsibility}

The discussions showed at least two different understandings of responsibility. First, responsibility was perceived as being responsible towards society and also as a critique of research without limits or boundaries. This means that the responsibility of research is about pursuing the aims of society and ensuring this by constant exchange with societal actors. Second, responsibility was about how research is conducted in order to ensure a certain standard and progress. This understanding was seen in contrast to the demands for more responsibility towards society.

RRI was not regarded as having much intrinsic or additional value for the discussions on responsibility. The concept can be related to many already widely debated and established practices such as the five RRI keys (Ethics, Engagement, Science Education, Gender and Open Access; as per the EC-understanding) but can also be understood as a new term overlapping with the already well-established concept of "sustainability". The implementation of RRI is well under way without being labelled in this way. This is particularly true regarding Engagement, Ethics and Gender. For instance, the German Government has initiated laws ensuring gender mainstreaming and setting concrete goals. This in turn, creates a setting in which most organisations have to develop or take up programmes on Gender, ensuring that this is approached somewhat systematically. In terms of Engagement and Ethics, there are already many established practices as well as increasing demands. In Germany, the demand for engagement in $\mathrm{S} \& \mathrm{~T}$ decision making has increased over the last years, obliging organisations to engage with societal actors in some way.

\section{Workshop outcomes}

Much of the discussion focused on questions about the implementation of RRI in research practices. Many of the points dealt with the conflict of increasing quantitative standards in research evaluation processes, with the mainly qualitatively assessed inclusion of various stakeholders in the research process. The research system does not incorporate these inclusive aspects in the evaluation process, resulting in difficulties to correctly assess the impact of research and researchers. Furthermore, the partici- pants saw the importance of the regulatory aspects of science that could enable initiatives towards more inclusion or responsibility, e. g. by regulating processes of exchange between experts and stakeholders. Yet, a top-down approach was not seen as overall useful due to the concept of autonomy in science and research, which is particularly important in the German context. Instead, evaluation criteria should be reassessed, opening up spaces for discussion where topics and challenges can be reframed. The actual establishment of RRI has to be done on the level of peer groups, and here the communication between different actors within the science system is needed.

The participants stressed the importance of cooperation on all levels in actually establishing responsibility. From the state and institutional level, participants demanded an agenda-setting and framing that incorporates responsibility and allows for exchange between researchers and societal actors. A top-down-approach was not considered useful, but the possibility to pursue a "cultural" change within research peer groups was seen as a way forward. This would require a particular framing that should be given priority in the research funding area.

This workshop could only touch on many of the issues surrounding RRI, its implementation and what this means in the German context. For the RRI-Practice project, which is conducting similar workshops across the world, it was a first step towards understanding how RRI is adapted in different contexts. Building on these workshops and other activities, the project will closely examine national, organisational as well as cultural aspects important for implementing RRI. This will also enable insights into a wider level of RRI as well as what forms of assessing science, technology and innovation can look like in a growing global context.

\section{References \\ Hahn, Julia; Ladikas, Miltos (2014): Responsible Research and Innovation: A Global Perspective. In: Enterprise and Work Innovation Studies, 10, IET/CESNOVA, pp.9-27. Download available at https://run.unl.pt/ bitstream/10362/16080/1/HahnLadikas-9-27.pdf, link checked on 08. 06.2017. Stilgoe, Jack; Owen, Richard; Macnaghten, Phil (2013): Developing a Framework For Responsible Innovation. In: Research Policy 42 (9), pp. 1568-1580. Download available at http://www.sciencedirect.com/science/ journal/00487333/42/9, link checked on 08.06.2017.}

\section{Further information}

"Responsible Research and Innovation in Practice"

(RRI-Practice), Duration: 2016-2019

Webpage: https://www.rri-practice.eu/

The project will review RRI-related work in 22 research

conducting and research funding organisations and

will develop RRI Outlooks outlining RRI objectives, targets

and indicators for each organisation. 